\title{
Difusi inovasi cerita prosa rakyat dalam aplikasi audiobuku
}

\author{
Evi Nursanti Rukmana ${ }^{1}$, Pawit M. Yusup ${ }^{2}$, Wina Erwina ${ }^{3}$ \\ 1,2,3 Dosen Prodi Ilmu Perpustakaan, Fakultas Ilmu Komunikasi, Universitas Padjadjaran \\ e-mail:evi.nursanti.r@gmail.com,pawitmy@gmail.com,wina.erwina@unpad.ac.id
}

\begin{abstract}
Folklore has derived from oral traditions in the community. For children, folklore can be a fun learning medium to learn about local culture. The presence of AudioBuku is a new alternative in reading books. It presents a collection of Indonesian folktales in audio. The purpose of this study is to analyze the diffusion process of innovation in folklore in the AudioBuku, which consists of processes of innovation, diffusion, and adoption. This research method uses a qualitative approach in the form of a case study. The results of the study state that in the process of innovation, an attractive AudioBuku can lead children to listen to folklore using sound. In addition, a collection of folklore can be accessed both free and paid. In the diffusion process, AudioBuku in smartphones is easily operated and accessed directly by children and parents. In the process of adoption, some children and parents become sustainable adopters and final adopters. Users who become sustainable adopters are those who can use AudioBuku continuously, while users who are called final adopters are those who use AudioBuku at a certain time. AudioBuku has provided learning facilities in the form of sound media to facilitate reading activities.
\end{abstract}

Keywords: Folklore; AudioBuku; Diffusion of Inovation

\begin{abstract}
ABSTRAK
Cerita rakyat adalah cerita yang dimiliki tiap daerah bersumber dari tradisi lisan di masyarakat. Bagi anak-anak, cerita rakyat dapat menjadi media belajar yang menyenangkan sekaligus belajar mengenai kebudayaan setempat. Kehadiran aplikasi AudioBuku menjadi alternatif dalam kegiatan membaca buku yang menghadirkan koleksi cerita rakyat khas Indonesia melalui suara (audio). Tujuan penelitian ini yakni menganalisis proses difusi inovasi dalam cerita rakyat dalam aplikasi AudioBuku, yang terdiri dari proses inovasi, proses difusi, dan proses adopsi. Metode penelitian ini menggunakan metode kualitatif melalui metode penelitian studi kasus. Hasil penelitian menyatakan bahwa dalam proses inovasi, tampilan AudioBuku yang menarik dapat mengarahkan anak-anak untuk mendengarkan cerita rakyat berupa suara. Selain itu, koleksi cerita rakyat dapat diakses tanpa dikenakan biaya dan dikenakan biaya. Dalam proses difusi, media AudioBuku dalam smartphone mudah dioperasikan dan diakses secara langsung oleh anak-anak dan orang tua. Di proses adopsi, beberapa anak dan orang tua dapat menjadi pengadopsi lestari dan pengadopsi akhir. Pengguna yang menjadi pengadopsi lestari ialah mereka dapat menggunakan AudioBuku secara terus menerus, sedangkan pengguna yang dinamakan pengadopsi akhir yakni mereka yang menggunakan AudioBuku di waktu tertentu saja. AudioBuku telah menyediakan fasilitas belajar berupa media suara dalam memudahkan kegiatan membaca.
\end{abstract}

Kata Kunci: Cerita rakyat; AudioBuku; Difusi inovasi 


\section{A. PENDAHULUAN}

Cerita prosa rakyat merupakan salah satu tema buku yang menceritakan kisah-kisah dari pelbagai daerah. Tiap tema, kisah, tokoh, dan setting menggambarkan kondisi daerah tersebut. Ini menjadikan cerita prosa rakyat mengandung nilai-nilai pendidikan bagi anakanak. Bagi anak-anak yang berusia balita hingga 7 tahun, cerita rakyat dapat berupa picture book. Anak-anak yang berusia 8-12 tahun, cerita rakyat dapat berupa kisah-kisah panjang atau novel.

Koleksi cerita prosa rakyat berbentuk cetak (print media) mampu menumbuhkan anak-anak untuk membaca dan bahkan belajar membaca melalui pengenalan huruf. Selain itu, melalui untaian kalimat dan gambar ternyata mampu menambah daya imajinasi anakanak. Hal ini didukung melalui pertumbuhan penerbitan buku cetak, yang bertema cerita prosa rakyat dari pelbagai daerah pun banyak diterbitkan. Walaupun begitu, koleksi bahan cetak ini masih memiliki kendala dalam mengaksesnya. Harga jual buku dari beberapa buku yang masih tinggi dan akses membacanya yang perlu memakan waktu. Anak-anak untuk membaca buku cetak, termasuk cerita prosa rakyat harus dalam kondisi santai dan fokus tidak mengerjakan hal lainnya. Melalui adanya kemajuan dalam teknologi komunikasi dan informasi, koleksi cerita prosa rakyat pun dikembangkan dari media cetak ke media suara (audio book). Media audio book menjadi salah satu semacam perpustakaan digital yang memberikan pelayanan suara dalam menceritakan kembali buku tersebut.

Salah satu aplikasi audio book di Indonesia yakni aplikasi Audiobuku, yang bisa dilakukan secara streaming dan hadir ke perangkat android. Aplikasi yang memiliki beragam tema buku, dapat didengarkan secara sekilas sebagai ringkasan, membeli buku dengan harga yang terjangkau, dan mengunduhnya beberapa buku tanpa dipungut biaya. Audiobuku menjadi salah satu pilihan dalam mengakses literatur, termasuk bagi anak-anak dalam mendengarkan dan memahami cerita rakyat dari pelbagai daerah. Misalnya, cerita rakyat berjudul "Timun Mas" yang dikenakan biaya Rp. 3000,00, melalui beragam cara pembayaran. Kemudahan yang dihadirkan Audiobuku pun ternyata dapat digunakan oleh para tuna netra dalam mengakses literatur. Anak-anak penyandang tuna netra dapat mendengarkan cerita prosa rakyat untuk belajar memahami kosakata Bahasa Indonesia dan sebagai media hiburan.

Berdasarkan hal ini, peneliti ingin membahas mengenai pencarian dan penggunaan koleksi cerita prosa rakyat dalam Audiobuku. Peneliti menganalisis bagaimana masyarakat menggunakan Audiobuku dalam mencari literatur cerita prosa rakyat lalu mendengarkan kisah dalam buku digital tersebut. Misalnya dalam penelitian Stern (2011), audio book berperan penting dalam menambah jenis koleksi perpustakaan. Subjek penelitian ini berada di perpustakaan perguruan tinggi, The LaGuardia Community College Library. Subjek penelitian ini berbeda dengan subjek penelitian yang kami teliti. Walaupun begitu, masih ada beberapa persamaannya dari segi pemanfaatan jenis audio book. Pertama, perpustakaan harus berjuang keras dalam memperkenalkan penggunaan audio book sebagai koleksi perpustakaan karena masih banyak yang nyaman membaca buku berjenis teks. Kedua, untuk memperkenalkan audio book, maka pustakawan memberikan audio book di setiap kelas pembelajaran sebagai tambahan media pembelajaran.

Dengan demikian, hadirnya audio book sebagai koleksi perpustakaan membuat pustakawan harus memiliki kebijakan sendiri supaya buku berjenis teks tetap digunakan pengguna. Teknologi tidak bisa dihindari, justru pustakawan harus bisa menyeimbangkannya. Begitu pun dalam aplikasi AudioBuku, pengguna harus belajar mengoperasikannya agar dapat mendengarkan secara utuh koleksinya. Maka, peneliti menggunakan teori difusi inovasi dalam melihat penilaian masyarakat dalam menggunakan 
Audiobuku. Teori ini merupakan proses komunikasi yang berlangsung antara pengguna dengan media teknologi yang digunakannya. Dalam perkembangannya di masyarakat, buku berbentuk audio muncul untuk memberikan pilihan dalam mengakses literatur selain buku berbentuk cetak. Audiobuku menjadi semacam inovasi bagi pengguna, termasuk anak-anak dalam mendengarkan cerita prosa rakyat.

Gray, Davis, and Liou (2017) menambahkan bahwa belajar melalui audio book menjadi gaya pembelajaran yang menarik. Selain itu, mahasiswa sebagai partisipan memiliki kemampuan dalam menggunakan audio book sehingga proses belajar menjadi mudah diterima mahasiswa. Mahasiswa dalan dunia perkuliahan memerlukan inovasi dalam media pembelajaran di kampus. Begitu pun dengan anak-anak, yang masih terus diberikan arahan dan bimbingan dalam belajar. Selain itu, Stern (2011) dalam penelitian berpendapat bahwa audio book yang diakses pengguna di perpustakaan perguruan tinggi mengalami perkembangan yang pesat. Pengguna mulai menggunakan beragam format audio book untuk memudahkan belajar, misalnya penguna akan mendengarkan salah satu novel Jane Austin untuk belajar dalam mata kuliah bahasa dan sastra. Dari hal ini, pengguna menggunakan audio book tak hanya untuk hiburan semata. Pengguna dapat belajar mengenai berbagai hal dari koleksi audio book. Begitu pun melalui aplikasi Audiobuku, pengguna khususnya anak-anak akan dirangsang untuk meningkatkan minat dalam membaca terutama dalam koleksi dari bentuk kearifan lokal.

\section{B. TINJAUAN PUSTAKA}

Bunanta (2008) menjelaskan kalau cerita prosa rakyat merupakan bentuk dari sastra tradisional, yang terdiri dari, "legenda, mite dan dongeng". Mite bercerita mengenai kisah dewa-dewi, asal usul dunia dan kisah di luar kehidupan manusia, misalnya cerita Dewa Sri di Budaya Sunda dan Ramayana di Budaya Jawa. Legenda disebut "bersifat sekuler (keduniawian)" (Bunanta 2008). Kisahnya terjadi di alam manusia yang kini ditinggali dan waktunya belum terlalu lampau. Danadjadja (1994) dalam Bunanta (2008) membedakan legenda menjadi, legenda keagamaan, legenda setempat, legenda alam ghaib dan legenda perseorangan. Lain halnya dalam dongeng. Dongeng bercerita mengenai manusia dan binatang di dunia, yang tidak benar-benar terjadi walaupun memiliki nilai-nilai moral dalam kehidupan.

Untuk anak-anak usia dini, cerita rakyat berbentuk cetak dihadirkan dalam buku bergambar (picture book). Picture book yakni, "Satu-satunya jenis buku yang dapat dijadikan sebuah sarana untuk menghasilkan sebuah karya seni tinggi, baik dari segi bahasa maupun dari segi ilustrasi-nya, juga dari tema ceritanya" (Bunanta 2008). Picture book disebut sebagai karya seni tinggi karena gambar yang dihadirkan dituntut bagus untuk dapat merepresentasikan isi cerita, misalnya gambar hasil lukisan. Selain itu, antara gambar harus memiliki korelasi dengan bahasa dan tema cerita.

Anak-anak usia dini yang belum mampu membaca dapat belajar mengenal kata, memahami gambar dan menyaring isi cerita dari cerita rakyat. Adanya perkembangan dunia digital, cerita rakyat pun mulai dihadirkan berbentuk audiobook. Ini menjadi suatu pilihan dalam kegiatan membaca tanpa harus membawa fisik bukunya. Walaupun, sebelumnya telah hadir bentuk elektronik buku (e-book). Namun, melalui audiobook, anakanak dapat belajar mendengarkan isi cerita untuk mengasah kemampuan berbicara.

Clark (2007) menambahkan, "Audio encourages different skills. It can be fun to listen to, and requires an emotional and sensual engagement, as well as some understanding of how sound can signal meaning. I explore the idea of sound as an alternative form of communication, dividing it into three sections: the oral or the spoken 
word, sound effects (silence and non-verbal effects) and music". Audiobook menghadirkan suasana yang berbeda dalam membaca. Suara dalam audiobook menjadi salah satu alternatif bentuk komunikasi yang terdiri dari komunikasi verbal, efek suara dan musik. Ketiga hal ini menjadi daya tarik utama pengguna audiobook.

Media audio sebenarnya merupakan bentuk dari komunikasi verbal atau lisan sehingga audio disebut media yang mampu melewati beberapa dekade. "The key change in attitude has been to recognise that the audiobook is a distinct medium in its own right rather than a poor relative of the printed book. There are even signs that the digital option is at last encouraging use of a medium that has been around for decades" (Rubery 2008). Hadirnya digital, menjadikan audio merambah merubah bentuk buku menjadi audiobook. Di dunia, perusahaan Amazon menciptakan aplikasi Audibel.com, dalam memberikan pilihan dalam membaca buku-buku fiksi. Indonesia sendiri, aplikasi Audiobuku, menjadi pionir sebagai media audio yang menghadirkan semua genre buku, termasuk cerita rakyat bagi anak-anak.

Kehadiran Audiobuku, telah membantu masyarakat, khususnya anak-anak Indonesia dalam mendengarkan dan memahami literatur khas Indonesia, yakni cerita prosa rakyat. Dari perpaduan komunikasi lisan, efek suara dan musik menjadi daya tarik anak-anak mempelajari cerita prosa rakyat. Penggunaan media audiobook ini menjadi inovasi dalam dunia literatur anak-anak. Mereka makin dimudahkan untuk mengakses buku berbentuk suara dengan harga yang terjangkau.

Maka, dapat dikatakan bahwa melalui Audiobuku, menjadi inovasi bagi dunia komunikasi. Rogers (1962) dalam LaMorte (2016) mengembangkan hal ini menjadi teori difusi inovasi, yakni,

"It originated in communication to explain how, over time, an idea or product gains momentum and diffuses (or spreads) through a specific population or social system. The end result of this diffusion is that people, as part of a social system, adopt a new idea, behavior, or product. Adoption means that a person does something differently than what they had previously (i.e., purchase or use a new product, acquire and perform a new behavior, etc.). The key to adoption is that the person must perceive the idea, behavior, or product as new or innovative. It is through this that diffusion is possible".

Teori ini menggambarkan bagaimana suatu produk komunikasi menjadi inovasi bagi individu atau kelompok bahkan sistem sosial di dalamnya. Inovasi dapat menjadi pembaharuan bagi masyarakat bila terjadi adopsi. Adopsi dapat diartikan sebagai, "Mengakui atau mengambil" (Endarmoko 2007). Masyarakat dapat mengadopsi Audiobuku dan menggunakan fasilitas-fasilitas dalam aplikasi tersebut. Sebelumnya, latar belakang masyarakat yang menggunakan Audiobuku akan terlihat. Bagaimana awalnya mereka mengakses media cetak menjadi bentuk audiobook. Kebutuhan mengakses buku di setiap tempat dan waktu menjadi pilihan tersendiri mengakses Audiobuku. Apalagi, inovasi literatur berbentuk audiobook ini dihadirkan dengan harga yang terjangkau. Pada akhirnya, mulai merubah tatanan sosial di masyarakat. Masyarakat kini dapat mengakses literatur melalui media suara menggunakan handphone dalam genggaman tangan sendiri. 

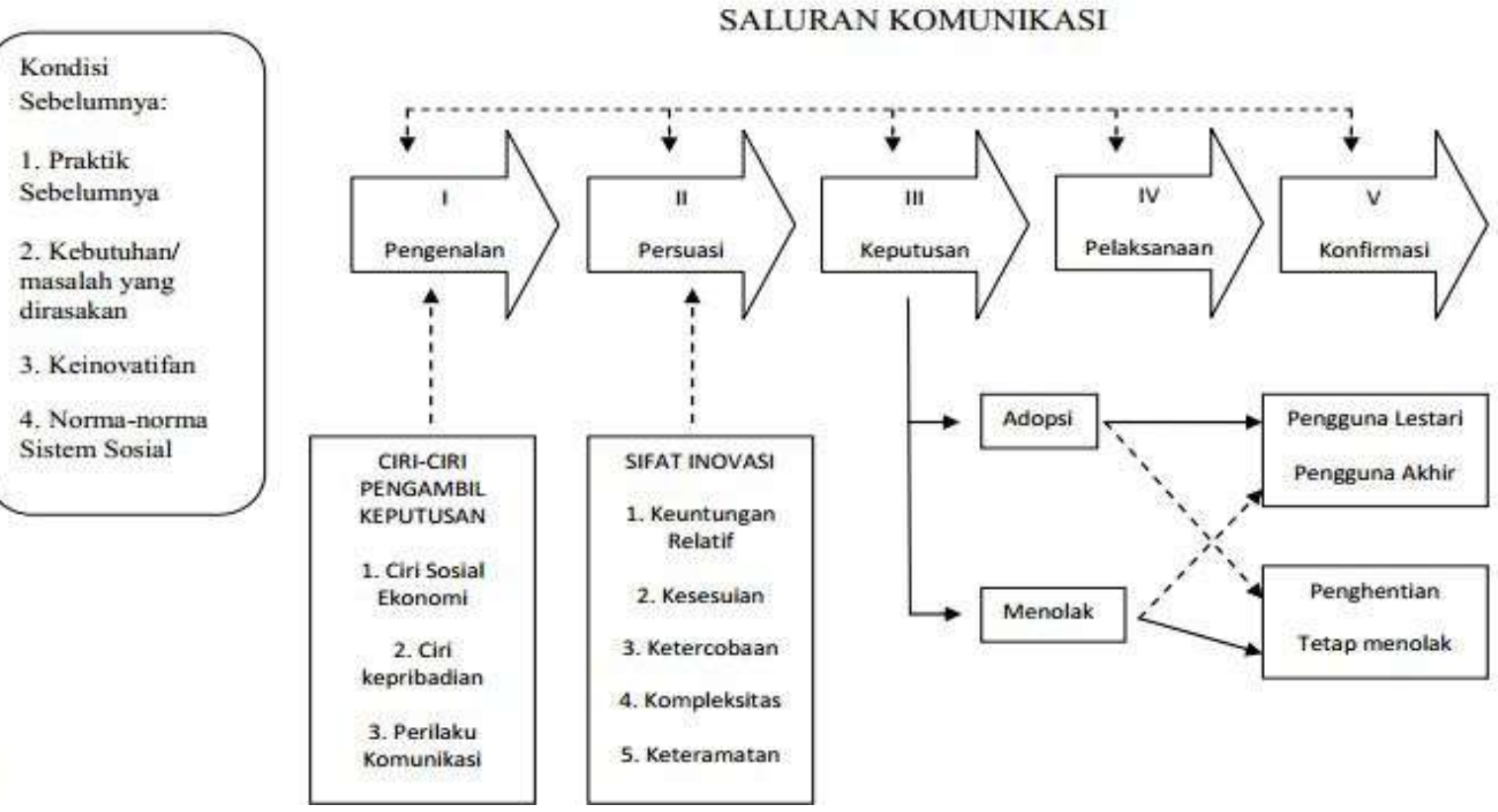

Gambar 1. Model Teori Difusi Inovasi Sumber: Sidik 2016

Prosesnya sendiri, dimulai dari proses pengenalan atau pengetahuan. Aida (2010) dalam Sidik (2016), mengatakan bahwa individu atau pengguna mulai menyadari inovasi dari produk dan mulai memahami fungsi produk tersebut. Ini bisa diamati dari sisi ekonomi, kepribadian dan perilaku komunikasi pengguna. Lalu, adanya proses persuasi. Persuasi berhubungan dengan, "sikap". Bahwa dari inovasi ini akan menimbulkan efek yang beragam di kalangan pengguna, dilihat dari keuntungan reatif, kesesuaian, ketercobaan, kompleksitas dan keteramatan atau mengamati.

Selanjutnya, proses keputusan. Pengguna Audiobuku memiliki pilihan untuk mengadopsi atau bahkan menolak. Adopsi berarti menerima informasi yang diberikan Audiobuku sedangkan menolak diartikan bahwa pengguna tidak mau menerima inovasi yang hadir dalam Audibuku. Proses ini dilanjutkan ke proses pelaksanaan atau penerapan. Pengguna mulai mengikuti prosedur atau acuan dalam menggunakan fasilitas Audiobuku walaupun di benak pengguna masih ada ketidakpastian saat menggunakannya. Hingga akhirnya, pengguna memastikan atau melakukan konfirmasi ketika menggunakan Audiobuku. Pengguna bisa membaca review dari para pengguna lainnya.

\section{METODE PENELITIAN}

Fenomena Audiobuku menjadi sebuah fenomena yang hadir dari perkembangan dunia digital. Untuk menganalisis hal ini, maka digunakan pendekatan kualitatif. Family Health International (2012) menyatakan bahwa pendekatan kualitatif mampu menggambarkan pengalaman seseorang dalam suatu fenomena tertentu. Fenomena bisa dari perilaku, kepercayaan, opini, emosi dan hubungan sesama individu atau relasi. Juga mampu menggambarkan faktor-faktor yang tidak bisa dihitung seperti agama, etnis, gender dan sosioekonomi. Dalam Audiobuku, fenomena yang dilihat adalah bagaimana proses difusi inovasi pengguna anak-anak dalam mendengarkan audiobook bertema cerita rakyat.

Berdasarkan hal ini, maka metode penelitian yang dipilih ialah studi kasus. MerriamWebster Dictionary's (2009) dalam Harrison, Birks, Franklin, \& Mills (2017) 
mendefinisikan studi kasus, "As an example that captures the key requisites in the context of research: an intensive analysis of an individual unit (as a person or community) stressing developmental factors in relation to environment". Metode penelitian studi kasus membantu individu menganalisis secara intensif dalam hubungan pengembangan diri di lingkungannya. Dalam Audiobuku, pengguna di era digital mulai menggunakan produk inovasi pembaharu sebagai pilihan dalam dunia literatur.

Fenomena hadirnya aplikasi AudioBuku merupakan terobosan terbaru dalam mendengarkan koleksi buku di mana pun pengguna berada. Ini merupakan fenemona yang unik karena pengguna memiliki pilihan lain dalam membaca buku yang awalnya buku teks. Dalam penelitian ini, kami melakukan penelitian pada aplikasi AudioBuku mengenai analisis difusi inovasi koleksi cerita rakyat pada AudioBuku. Ruzzene (2011) memaparkan 8 tahap dalam menganalisa fenomena menggunakan metode penelitian studi kasus. Pertama, peneliti mengenalisis masalah dalam penelitian dan diseuaikan dengan konteks kajian. Fenomena yang dipilih krusial dan berdampak bagi lingkungan sosial. Fenomena aplikasi AudioBuku sebagai buku elektronik yang dihadirkan secara digital membantu pengguna membaca buku melalui mendengarkan. Tentunya, dari AudioBuku menjadi salah satu bentuk perkembangan teknologi di dunia literatur. Pengguna dapat terangsang untuk mendengarkan koleksi buku lalu termotivasi membaca buku secara fisik.

Kedua, peneliti harus menghasilkan hasil penelitian yang akurat dan valid, maka peneliti harus memiliki ketertarikan terhadap fenomena yang sedang diteliti. Salah satu koleksi aplikasi AudioBuku yang diteliti ialah cerita rakyat, sebagai salah satu bentuk tradisi lisan yang diceritak kembali. Bagi anak-anak, cerita rakyat dapat menjadi media belajar yang menyenangkan dalam memahami kosakata bahasa, pengenalan tokoh, setting, alur dll. Apalagi, cerita rakyat yang dihadirkan melalui suara. Anak-anak dapat mendengar langsung suara khas dari tokoh-tokohnya. Dari hal ini, cerita rakyat akan merangsang anak-anak untuk gemar membaca. Peneliti menyakini bahwa cerita rakyat yang dihadirkan dalam media apa pun, termasuk audio book akan membantu anak-anak memahami dunia literatur. Maka, AudioBuku menjadi sumber literatur yang penting dalam proses belajar anak-anak.

Ketiga, peneliti harus merumuskan pertanyaan penelitian secara jelas dan jenis kasus yang digunakan. Peneliti merumuskan pertanyaan penelitian yakni bagaimana proses inovasi, difusi dan adopsi pengguna dalam menggunakan koleksi cerita rakyat pada aplikasi AudioBuku. Dalam penelitian ini menggunakan satu kasus (single case) dalam studi kasus, yakni fenomena penggunaan audio book pada aplikasi AudioBuku. Keempat, pemilihan data yang akan digunakan peneliti. Untuk mendapatkan data yang akurat dan valid, maka peneliti menelusur aplikasi tampilan AudioBuku dan wawancara dengan pemilik aplikasi dan pengguna.

Kelima, pengolahan data melalui 6 sumber data, diantaranya observasi partisipan, oberservasi non-partisipan, wawancara, studi literatur, dokumen, dan artefak fisik. Observasi ditelusur langsung pada aplikasi AudioBuku dan melihat keaktifan secara langsung pengguna. Peneliti pun melakukan wawancara pada pemilik sekaligus pengembang aplikasi AudioBuku dan para pengguna. Keenam, analisis data. Dalam kegiatan analisis data, peneliti membuat transkrip hasil wawancara untuk bahan menuangkan tulisan. Ketujuh, identifikasi kembali data. Dalam hal ini, peneliti melakukan analisis kembali data dari transkrip hasil wawancara dengan suara wawancara secara langsung Kedelapan, analisis data yang relevan dan sesuai temuan penelitia. Peneliti membaca kembali hasil temuan data di lapangan dengan tulisan yang telah disusun lalu disesuaikan dengan pertanyaan penelitian. 


\section{HASIL DAN PEMBAHASAN}

AudioBuku adalah media audiobook yang menyediakan fasilitas mendengarkan buku melalui aplikasi playstore dan Appstore di handphone (HP). AudioBuku menjadi sebuah alternatif untuk mendapatkan pengetahuan dari berbagai rujukan melalui mendengarkan. Hal inilah yang menjadi tujuan pencetus dan pemilik AudioBuku, Muhammad Taufik, dari PT. Edikasi Media Indonesia membuat dan terus mengembangkan aplikasi ini.

AudioBuku memudahkan masyarakat dalam membaca buku. Awalnya, kegiatan membaca buku berupa jenis teks. Lalu, seiring perkembangan digital, hadir pula buku berjenis electronic book (e-book). Kedua jenis buku ini memiliki kelebihan dan kekurangan masing-masing. Buku teks dapat dibaca di tempat yang tenang dan tempat yang kering, sedangkan e-book untuk membacanya membutuhkan media digital sebagai alat bacanya. Dari kelemahan kedua jenis buku ini, maka AudioBuku menawarkan fasilitas membaca buku melalui suara. Masyarakat tinggal mengunduh aplikasi AudioBuku di HP, lalu memilih buku yang ingin didengar secara gratis, download atau membeli buku yang diinginkan.

Salah satu koleksi AudioBuku yang dapat menumbuhkan minat membaca bagi anakanak ialah cerita rakyat. Pengguna koleksi cerita rakyat, untuk mendengarkan secara penuh suaranya, ada yang harus berbayar dan gratis diunduh. Koleksi cerita rakyat yang dikenakan biaya berasal dari pengarang Paberland, Kastari Animation Studios dan Segala Sumber, sedangkan koleksi yang gratis dari BPMRPK Kemendikbud. Berikut rincian koleksi cerita rakyat.

Tabel 1. Data koleksi cerita rakyat

\begin{tabular}{|c|c|c|c|}
\hline No & Judul buku & Penulis & Narator \\
\hline 1 & $\begin{array}{l}\text { Kumpulan Dongeng Cerita Rakyat dan Legenda } \\
\text { Volume } 1\end{array}$ & Paberland & Dyah Ayu Kumalasari \\
\hline 2 & $\begin{array}{l}\text { Kumpulan Dongeng Cerita Rakyat dan Legenda } \\
\text { Volume } 2\end{array}$ & Paberland & Dyah Ayu Kumalasari \\
\hline 3 & $\begin{array}{l}\text { Kumpulan Dongeng Cerita Rakyat dan Legenda } \\
\text { Volume } 3\end{array}$ & Paberland & Dyah Ayu Kumalasari \\
\hline 4 & $\begin{array}{l}\text { Kumpulan Dongeng Cerita Rakyat dan Legenda } \\
\text { Volume } 4\end{array}$ & Paberland & Dyah Ayu Kumalasari \\
\hline 5 & $\begin{array}{l}\text { Kumpulan Dongeng Cerita Rakyat dan Legenda } \\
\text { Volume } 5\end{array}$ & Paberland & Dyah Ayu Kumalasari \\
\hline 6 & $\begin{array}{l}\text { Kumpulan Dongeng Cerita Rakyat dan Legenda } \\
\text { Volume } 6\end{array}$ & Paberland & Dyah Ayu Kumalasari \\
\hline 7 & Cerita Rakyat Nusantara Vol. 1 & Paberland & Dyah Ayu Kumalasari \\
\hline 8 & Cerita Rakyat Nusantara Vol. 2 & Paberland & Dyah Ayu Kumalasari \\
\hline 9 & Cerita Rakyat Nusantara Vol. 3 & Paberland & Dyah Ayu Kumalasari \\
\hline 10 & Cenderawasih & Paberland & Dyah Ayu Kumalasari \\
\hline 11 & Syeh Bela Belu & $\begin{array}{l}\text { BPMRPK } \\
\text { Kemendikbud }\end{array}$ & $\begin{array}{l}\text { BPMRPK } \\
\text { Kemendikbud }\end{array}$ \\
\hline 12 & Sunan Kalijaga dan Kyai Geseng & $\begin{array}{l}\text { BPMRPK } \\
\text { Kemendikbud }\end{array}$ & $\begin{array}{l}\text { BPMRPK } \\
\text { Kemendikbud }\end{array}$ \\
\hline 13 & Watu Ulo & $\begin{array}{l}\text { BPMRPK } \\
\text { Kemendikbud }\end{array}$ & $\begin{array}{l}\text { BPMRPK } \\
\text { Kemendikbud }\end{array}$ \\
\hline 14 & Ular n Daung & $\begin{array}{l}\text { BPMRPK } \\
\text { Kemendikbud }\end{array}$ & $\begin{array}{l}\text { BPMRPK } \\
\text { Kemendikbud }\end{array}$ \\
\hline 15 & Tragedi di Maibit & $\begin{array}{l}\text { BPMRPK } \\
\text { Kemendikbud }\end{array}$ & $\begin{array}{l}\text { BPMRPK } \\
\text { Kemendikbud }\end{array}$ \\
\hline 16 & Toar dan Lumimuut & $\begin{array}{l}\text { BPMRPK } \\
\text { Kemendikbud }\end{array}$ & $\begin{array}{l}\text { BPMRPK } \\
\text { Kemendikbud }\end{array}$ \\
\hline 17 & Tiwoq Iwoq & $\begin{array}{l}\text { BPMRPK } \\
\text { Kemendikbud }\end{array}$ & $\begin{array}{l}\text { BPMRPK } \\
\text { Kemendikbud }\end{array}$ \\
\hline
\end{tabular}




\begin{tabular}{|c|c|c|c|}
\hline 18 & Tanduk Panjang & $\begin{array}{l}\text { BPMRPK } \\
\text { Kemendikbud }\end{array}$ & $\begin{array}{l}\text { BPMRPK } \\
\text { Kemendikbud }\end{array}$ \\
\hline 19 & Sunan Bonang dan Brahmana Sakti & $\begin{array}{l}\text { BPMRPK } \\
\text { Kemendikbud }\end{array}$ & $\begin{array}{l}\text { BPMRPK } \\
\text { Kemendikbud }\end{array}$ \\
\hline 20 & Si Unyang Bulan & $\begin{array}{l}\text { BPMRPK } \\
\text { Kemendikbud }\end{array}$ & $\begin{array}{l}\text { BPMRPK } \\
\text { Kemendikbud }\end{array}$ \\
\hline 21 & Siluman Biru & $\begin{array}{l}\text { BPMRPK } \\
\text { Kemendikbud }\end{array}$ & $\begin{array}{l}\text { BPMRPK } \\
\text { Kemendikbud }\end{array}$ \\
\hline 22 & Siuk Bimbim dan Siuk Bambam & $\begin{array}{l}\text { BPMRPK } \\
\text { Kemendikbud }\end{array}$ & $\begin{array}{l}\text { BPMRPK } \\
\text { Kemendikbud }\end{array}$ \\
\hline 23 & Si Skolong & $\begin{array}{l}\text { BPMRPK } \\
\text { Kemendikbud }\end{array}$ & $\begin{array}{l}\text { BPMRPK } \\
\text { Kemendikbud }\end{array}$ \\
\hline 24 & Si Sigarlaki dan Si Limbat & $\begin{array}{l}\text { BPMRPK } \\
\text { Kemendikbud }\end{array}$ & $\begin{array}{l}\text { BPMRPK } \\
\text { Kemendikbud }\end{array}$ \\
\hline 25 & Si Sarioto & $\begin{array}{l}\text { BPMRPK } \\
\text { Kemendikbud }\end{array}$ & $\begin{array}{l}\text { BPMRPK } \\
\text { Kemendikbud }\end{array}$ \\
\hline 26 & Si Pahit Lidah & $\begin{array}{l}\text { BPMRPK } \\
\text { Kemendikbud }\end{array}$ & $\begin{array}{l}\text { BPMRPK } \\
\text { Kemendikbud }\end{array}$ \\
\hline 27 & Si Kintan & $\begin{array}{l}\text { BPMRPK } \\
\text { Kemendikbud }\end{array}$ & $\begin{array}{l}\text { BPMRPK } \\
\text { Kemendikbud }\end{array}$ \\
\hline 28 & Si Buan dan Si Ugui & $\begin{array}{l}\text { BPMRPK } \\
\text { Kemendikbud }\end{array}$ & $\begin{array}{l}\text { BPMRPK } \\
\text { Kemendikbud }\end{array}$ \\
\hline 29 & Sang Jungking dan Burung Dedek Seri 2 & $\begin{array}{l}\text { BPMRPK } \\
\text { Kemendikbud }\end{array}$ & $\begin{array}{l}\text { BPMRPK } \\
\text { Kemendikbud }\end{array}$ \\
\hline 30 & Sang Jungking dan Burung Dedek Seri 2 & $\begin{array}{l}\text { BPMRPK } \\
\text { Kemendikbud }\end{array}$ & $\begin{array}{l}\text { BPMRPK } \\
\text { Kemendikbud }\end{array}$ \\
\hline 31 & Sandubaya dan Lala Seruni & $\begin{array}{l}\text { BPMRPK } \\
\text { Kemendikbud }\end{array}$ & $\begin{array}{l}\text { BPMRPK } \\
\text { Kemendikbud }\end{array}$ \\
\hline 32 & Raja Kayu & $\begin{array}{l}\text { BPMRPK } \\
\text { Kemendikbud }\end{array}$ & $\begin{array}{l}\text { BPMRPK } \\
\text { Kemendikbud }\end{array}$ \\
\hline 33 & Roro Jonggrang Versi 2 & $\begin{array}{l}\text { BPMRPK } \\
\text { Kemendikbud }\end{array}$ & $\begin{array}{l}\text { BPMRPK } \\
\text { Kemendikbud }\end{array}$ \\
\hline 34 & Raja Burung Parkit & $\begin{array}{l}\text { BPMRPK } \\
\text { Kemendikbud }\end{array}$ & $\begin{array}{l}\text { BPMRPK } \\
\text { Kemendikbud }\end{array}$ \\
\hline 35 & Raden Wiratmoyo dan Sri Huning & $\begin{array}{l}\text { BPMRPK } \\
\text { Kemendikbud }\end{array}$ & $\begin{array}{l}\text { BPMRPK } \\
\text { Kemendikbud }\end{array}$ \\
\hline 36 & Raden Pandanaran & $\begin{array}{l}\text { BPMRPK } \\
\text { Kemendikbud }\end{array}$ & $\begin{array}{l}\text { BPMRPK } \\
\text { Kemendikbud }\end{array}$ \\
\hline 37 & Raden Mas Pahit & $\begin{array}{l}\text { BPMRPK } \\
\text { Kemendikbud }\end{array}$ & $\begin{array}{l}\text { BPMRPK } \\
\text { Kemendikbud }\end{array}$ \\
\hline 38 & Putri Tandampalik & $\begin{array}{l}\text { BPMRPK } \\
\text { Kemendikbud }\end{array}$ & $\begin{array}{l}\text { BPMRPK } \\
\text { Kemendikbud }\end{array}$ \\
\hline 39 & Putri Sarang Burung Pallas Baruni & $\begin{array}{l}\text { BPMRPK } \\
\text { Kemendikbud }\end{array}$ & $\begin{array}{l}\text { BPMRPK } \\
\text { Kemendikbud }\end{array}$ \\
\hline 40 & Putri Petung & $\begin{array}{l}\text { BPMRPK } \\
\text { Kemendikbud }\end{array}$ & $\begin{array}{l}\text { BPMRPK } \\
\text { Kemendikbud }\end{array}$ \\
\hline 41 & Putri Papu & $\begin{array}{l}\text { BPMRPK } \\
\text { Kemendikbud }\end{array}$ & $\begin{array}{l}\text { BPMRPK } \\
\text { Kemendikbud }\end{array}$ \\
\hline 42 & Putri Mas & $\begin{array}{l}\text { BPMRPK } \\
\text { Kemendikbud }\end{array}$ & $\begin{array}{l}\text { BPMRPK } \\
\text { Kemendikbud }\end{array}$ \\
\hline 43 & Putri Mandalika & $\begin{array}{l}\text { BPMRPK } \\
\text { Kemendikbud }\end{array}$ & $\begin{array}{l}\text { BPMRPK } \\
\text { Kemendikbud }\end{array}$ \\
\hline 44 & Putri Kesumba & $\begin{array}{l}\text { BPMRPK } \\
\text { Kemendikbud }\end{array}$ & $\begin{array}{l}\text { BPMRPK } \\
\text { Kemendikbud }\end{array}$ \\
\hline 45 & Putri Ngerit jadi Rebutan & $\begin{array}{l}\text { BPMRPK } \\
\text { Kemendikbud }\end{array}$ & $\begin{array}{l}\text { BPMRPK } \\
\text { Kemendikbud }\end{array}$ \\
\hline
\end{tabular}




\begin{tabular}{|c|c|c|c|}
\hline 46 & Putera Mahkota Amat Mude & $\begin{array}{l}\text { BPMRPK } \\
\text { Kemendikbud }\end{array}$ & $\begin{array}{l}\text { BPMRPK } \\
\text { Kemendikbud }\end{array}$ \\
\hline 47 & Patepayan Minak Jingge & $\begin{array}{l}\text { BPMRPK } \\
\text { Kemendikbud }\end{array}$ & $\begin{array}{l}\text { BPMRPK } \\
\text { Kemendikbud }\end{array}$ \\
\hline 48 & Panji Semirang & $\begin{array}{l}\text { BPMRPK } \\
\text { Kemendikbud }\end{array}$ & $\begin{array}{l}\text { BPMRPK } \\
\text { Kemendikbud }\end{array}$ \\
\hline 49 & Panglima Sendong & $\begin{array}{l}\text { BPMRPK } \\
\text { Kemendikbud }\end{array}$ & $\begin{array}{l}\text { BPMRPK } \\
\text { Kemendikbud }\end{array}$ \\
\hline 50 & Pangeran Biawak versi 2 & $\begin{array}{l}\text { BPMRPK } \\
\text { Kemendikbud }\end{array}$ & $\begin{array}{l}\text { BPMRPK } \\
\text { Kemendikbud }\end{array}$ \\
\hline 51 & Pak Lebai Malang & $\begin{array}{l}\text { BPMRPK } \\
\text { Kemendikbud }\end{array}$ & $\begin{array}{l}\text { BPMRPK } \\
\text { Kemendikbud }\end{array}$ \\
\hline 52 & Nyai Ratu Kidul & $\begin{array}{l}\text { BPMRPK } \\
\text { Kemendikbud }\end{array}$ & $\begin{array}{l}\text { BPMRPK } \\
\text { Kemendikbud }\end{array}$ \\
\hline 53 & Ni Tiwas dan Ni Sugih & $\begin{array}{l}\text { BPMRPK } \\
\text { Kemendikbud }\end{array}$ & $\begin{array}{l}\text { BPMRPK } \\
\text { Kemendikbud }\end{array}$ \\
\hline 54 & Moko Sambur & $\begin{array}{l}\text { BPMRPK } \\
\text { Kemendikbud }\end{array}$ & $\begin{array}{l}\text { BPMRPK } \\
\text { Kemendikbud }\end{array}$ \\
\hline 55 & Mitiriwu & $\begin{array}{l}\text { BPMRPK } \\
\text { Kemendikbud }\end{array}$ & $\begin{array}{l}\text { BPMRPK } \\
\text { Kemendikbud }\end{array}$ \\
\hline 56 & Merpati dan Semut & $\begin{array}{l}\text { BPMRPK } \\
\text { Kemendikbud }\end{array}$ & $\begin{array}{l}\text { BPMRPK } \\
\text { Kemendikbud }\end{array}$ \\
\hline 57 & Meriam Ki dan Nyai Setomi & $\begin{array}{l}\text { BPMRPK } \\
\text { Kemendikbud }\end{array}$ & $\begin{array}{l}\text { BPMRPK } \\
\text { Kemendikbud }\end{array}$ \\
\hline 58 & Megat Merai Kandis & $\begin{array}{l}\text { BPMRPK } \\
\text { Kemendikbud }\end{array}$ & $\begin{array}{l}\text { BPMRPK } \\
\text { Kemendikbud }\end{array}$ \\
\hline 59 & Malin Deman & $\begin{array}{l}\text { BPMRPK } \\
\text { Kemendikbud }\end{array}$ & $\begin{array}{l}\text { BPMRPK } \\
\text { Kemendikbud }\end{array}$ \\
\hline 60 & Makam Imogiri & $\begin{array}{l}\text { BPMRPK } \\
\text { Kemendikbud }\end{array}$ & $\begin{array}{l}\text { BPMRPK } \\
\text { Kemendikbud }\end{array}$ \\
\hline 61 & Lindung Bulan & $\begin{array}{l}\text { BPMRPK } \\
\text { Kemendikbud }\end{array}$ & $\begin{array}{l}\text { BPMRPK } \\
\text { Kemendikbud }\end{array}$ \\
\hline 62 & Legenda Tuan Sormaliat & $\begin{array}{l}\text { BPMRPK } \\
\text { Kemendikbud }\end{array}$ & $\begin{array}{l}\text { BPMRPK } \\
\text { Kemendikbud }\end{array}$ \\
\hline 63 & Legenda Tingi Raja & $\begin{array}{l}\text { BPMRPK } \\
\text { Kemendikbud }\end{array}$ & $\begin{array}{l}\text { BPMRPK } \\
\text { Kemendikbud }\end{array}$ \\
\hline 64 & Legenda Sultan Domas & $\begin{array}{l}\text { BPMRPK } \\
\text { Kemendikbud }\end{array}$ & $\begin{array}{l}\text { BPMRPK } \\
\text { Kemendikbud }\end{array}$ \\
\hline 65 & Legenda Danau Toba & $\begin{array}{l}\text { BPMRPK } \\
\text { Kemendikbud }\end{array}$ & $\begin{array}{l}\text { BPMRPK } \\
\text { Kemendikbud }\end{array}$ \\
\hline 66 & Layang Sinandung & $\begin{array}{l}\text { BPMRPK } \\
\text { Kemendikbud }\end{array}$ & $\begin{array}{l}\text { BPMRPK } \\
\text { Kemendikbud }\end{array}$ \\
\hline 67 & Kusuma dan Gunung Bromo & $\begin{array}{l}\text { BPMRPK } \\
\text { Kemendikbud }\end{array}$ & $\begin{array}{l}\text { BPMRPK } \\
\text { Kemendikbud }\end{array}$ \\
\hline 68 & Ki Ageng Jengrana & $\begin{array}{l}\text { BPMRPK } \\
\text { Kemendikbud }\end{array}$ & $\begin{array}{l}\text { BPMRPK } \\
\text { Kemendikbud }\end{array}$ \\
\hline 69 & Kerio Panting & $\begin{array}{l}\text { BPMRPK } \\
\text { Kemendikbud }\end{array}$ & $\begin{array}{l}\text { BPMRPK } \\
\text { Kemendikbud }\end{array}$ \\
\hline 70 & Kerajaan Kota Kapur & $\begin{array}{l}\text { BPMRPK } \\
\text { Kemendikbud }\end{array}$ & $\begin{array}{l}\text { BPMRPK } \\
\text { Kemendikbud }\end{array}$ \\
\hline 71 & Kepala Lading Putri Bungsu & $\begin{array}{l}\text { BPMRPK } \\
\text { Kemendikbud }\end{array}$ & $\begin{array}{l}\text { BPMRPK } \\
\text { Kemendikbud }\end{array}$ \\
\hline 72 & Kepahlawanan Ranggalawe & $\begin{array}{l}\text { BPMRPK } \\
\text { Kemendikbud }\end{array}$ & $\begin{array}{l}\text { BPMRPK } \\
\text { Kemendikbud }\end{array}$ \\
\hline 73 & Kembang Ander Nyawe & $\begin{array}{l}\text { BPMRPK } \\
\text { Kemendikbud }\end{array}$ & $\begin{array}{l}\text { BPMRPK } \\
\text { Kemendikbud }\end{array}$ \\
\hline
\end{tabular}




\begin{tabular}{|c|c|c|c|}
\hline 74 & Kebo Iwa dan Sumur Majapahit & $\begin{array}{l}\text { BPMRPK } \\
\text { Kemendikbud }\end{array}$ & $\begin{array}{l}\text { BPMRPK } \\
\text { Kemendikbud }\end{array}$ \\
\hline 75 & Kebo Iwa & $\begin{array}{l}\text { BPMRPK } \\
\text { Kemendikbud }\end{array}$ & $\begin{array}{l}\text { BPMRPK } \\
\text { Kemendikbud }\end{array}$ \\
\hline 76 & Joko Tole & $\begin{array}{l}\text { BPMRPK } \\
\text { Kemendikbud }\end{array}$ & $\begin{array}{l}\text { BPMRPK } \\
\text { Kemendikbud }\end{array}$ \\
\hline 77 & Joko Dolog & $\begin{array}{l}\text { BPMRPK } \\
\text { Kemendikbud }\end{array}$ & $\begin{array}{l}\text { BPMRPK } \\
\text { Kemendikbud }\end{array}$ \\
\hline 78 & Jaranan Turonggo Yaksa & $\begin{array}{l}\text { BPMRPK } \\
\text { Kemendikbud }\end{array}$ & $\begin{array}{l}\text { BPMRPK } \\
\text { Kemendikbud }\end{array}$ \\
\hline 79 & Jaka Tarub versi 2 & $\begin{array}{l}\text { BPMRPK } \\
\text { Kemendikbud }\end{array}$ & $\begin{array}{l}\text { BPMRPK } \\
\text { Kemendikbud }\end{array}$ \\
\hline 80 & Jaka Kendil & $\begin{array}{l}\text { BPMRPK } \\
\text { Kemendikbud }\end{array}$ & $\begin{array}{l}\text { BPMRPK } \\
\text { Kemendikbud }\end{array}$ \\
\hline 81 & Gunung Orak Arik & $\begin{array}{l}\text { BPMRPK } \\
\text { Kemendikbud }\end{array}$ & $\begin{array}{l}\text { BPMRPK } \\
\text { Kemendikbud }\end{array}$ \\
\hline 82 & Tapa Tuladenggi dan Patunggo & $\begin{array}{l}\text { BPMRPK } \\
\text { Kemendikbud }\end{array}$ & $\begin{array}{l}\text { BPMRPK } \\
\text { Kemendikbud }\end{array}$ \\
\hline 83 & Taktik Perang Caadara & $\begin{array}{l}\text { BPMRPK } \\
\text { Kemendikbud }\end{array}$ & $\begin{array}{l}\text { BPMRPK } \\
\text { Kemendikbud }\end{array}$ \\
\hline 84 & Sangkuriang & $\begin{array}{l}\text { BPMRPK } \\
\text { Kemendikbud }\end{array}$ & $\begin{array}{l}\text { BPMRPK } \\
\text { Kemendikbud }\end{array}$ \\
\hline 85 & Baturaden & $\begin{array}{l}\text { BPMRPK } \\
\text { Kemendikbud }\end{array}$ & $\begin{array}{l}\text { BPMRPK } \\
\text { Kemendikbud }\end{array}$ \\
\hline 86 & Asal Usul nama Bitung & $\begin{array}{l}\text { BPMRPK } \\
\text { Kemendikbud }\end{array}$ & $\begin{array}{l}\text { BPMRPK } \\
\text { Kemendikbud }\end{array}$ \\
\hline 87 & Timun mas versi 2 & $\begin{array}{ll}\text { Kastari } & \text { Animation } \\
\text { Studio } & \end{array}$ & $\begin{array}{ll}\text { Kastari } & \text { Animation } \\
\text { Studio } & \end{array}$ \\
\hline 88 & Sangkuriang dan Tangkuban Perahu & $\begin{array}{l}\text { Kastari Animation } \\
\text { Studio }\end{array}$ & $\begin{array}{l}\text { Kastari Animation } \\
\text { Studio }\end{array}$ \\
\hline 89 & Roro Jonggrang & $\begin{array}{ll}\text { Kastari } & \text { Animation } \\
\text { Studio } & \end{array}$ & $\begin{array}{l}\text { Kastari } \quad \text { Animation } \\
\text { Studio }\end{array}$ \\
\hline 90 & Reog Ponorogo & $\begin{array}{ll}\text { Kastari } & \text { Animation } \\
\text { Studio } & \end{array}$ & $\begin{array}{ll}\text { Kastari } & \text { Animation } \\
\text { Studio } & \end{array}$ \\
\hline 91 & Pangeran Biawak & $\begin{array}{l}\text { Kastari Animation } \\
\text { Studio }\end{array}$ & Animation \\
\hline 92 & Malin Kundang & $\begin{array}{ll}\text { Kastari } & \text { Animation } \\
\text { Studio } & \\
\end{array}$ & Animation \\
\hline 93 & Keong Mas & $\begin{array}{ll}\text { Kastari } & \text { Animation } \\
\text { Studio } & \end{array}$ & $\begin{array}{l}\text { Kastari Animation } \\
\text { Studio }\end{array}$ \\
\hline 94 & Asal Mula Danau Toba & $\begin{array}{ll}\text { Kastari } & \text { Animation } \\
\text { Studio } & \\
\end{array}$ & $\begin{array}{l}\text { Kastari Animation } \\
\text { Studio }\end{array}$ \\
\hline 95 & Cindelaras versi 2 & $\begin{array}{l}\text { Kastari Animation } \\
\text { Studio }\end{array}$ & $\begin{array}{l}\text { Kastari Animation } \\
\text { Studio }\end{array}$ \\
\hline 96 & Bawang Merah Bawang Putih & $\begin{array}{ll}\text { Kastari } & \text { Animation } \\
\text { Studio } & \\
\end{array}$ & $\begin{array}{ll}\text { Kastari } & \text { Animation } \\
\text { Studio } & \\
\end{array}$ \\
\hline 97 & Batu Berdaun & $\begin{array}{ll}\text { Kastari } & \text { Animation } \\
\text { Studio } & \end{array}$ & $\begin{array}{ll}\text { Kastari } & \text { Animation } \\
\text { Studio } & \end{array}$ \\
\hline 98 & Timun Mas & Segala Sumber & Dyan Tedjo dkk. \\
\hline 99 & Sawunggaling & Segala Sumber & Tim Harilab Studio \\
\hline 100 & Cindelaras & Segala Sumber & Tim Harilab Studio \\
\hline 101 & Jaka Tarub & Segala Sumber & Dyan Tedjo dkk. \\
\hline 102 & Ciung Wanara & Segala Sumber & Jhoni \& Nandang K. \\
\hline
\end{tabular}

Sumber: Edifikasi Media Indonesia 2019

Berdasarkan data di atas, terdapat 102 judul koleksi cerita rakyat dari 3 pengarang yang berbeda. Ada beberapa judul cerita rakyat yang sama, misalnya Timun Mas dengan 
pengarang dan narator yang berbeda. Anak-anak yang mendengarkan cerita rakyat dalam AudioBuku akan berimajinasi seperti kegiatan membaca buku. AudioBuku hanya menampilkan cover buku saja untuk mewakili isi dari cerita tersebut. Selebihnya, anakanak akan berimajinasi mengenai tampilan tokoh, seting, dan adegan di tiap dialognya. Dari teknik membaca buku melalui suara ini, tidak hanya ditujukan bagi anak-anak penyandang disabilitas saja. Tapi, anak-anak dapat mendengarkan suara dari isi buku di mana pun dan kapan pun saja. Tidak ada batasan tempat dan waktu. Anak-anak bisa mendengarkan AudioBuku ketika mereka bermain di luar atau aktifitas olahraga. Anakanak tinggal mengaktfikan AudioBuku di HP lalu mengeraskan volumenya saja.

Dari fenomena ini, peran AudioBuku bukan menggeser peranan buku berjenis teks, tapi melengkapi kegiatan membaca melalui alunan suara. Tentunya, anak-anak akan termotivasi untuk membaca buku berjenis teks di waktu mereka memiliki waktu senggang. Handphone (HP) sebagai media komunikasi dapat menjadi media belajar yang menarik dan mendidik bagi anak-anak. Ini pun dapat menjadi solusi ketika anak-anak menyukai permainan online (game) dan video di channel Youtube.

Dalam dunia literatur Indonesia, masyarakat mulai dari jaman pra-sejarah hingga Folklore has derived from oral traditions in the community. For children, folklore can be a fun learning medium to learn about local culture. The presence of AudioBuku is a new alternative in reading books. It presents a collection of Indonesian folktales in audio. The purpose of this study is to analyze the diffusion process of innovation in folklore in the AudioBuku, which consists of processes of innovation, diffusion, and adoption. This research method uses a qualitative approach in the form of a case study. The results of the study state that in the process of innovation, an attractive AudioBuku can lead children to listen to folklore using sound. In addition, a collection of folklore can be accessed both free and paid. In the diffusion process, AudioBuku in smartphones is easily operated and accessed directly by children and parents. In the process of adoption, some children and parents become sustainable adopters and final adopters. Users who become sustainable adopters are those who can use AudioBuku continuously, while users who are called final adopters are those who use AudioBuku at a certain time. AudioBuku has provided learning facilities in the form of sound media to facilitate reading activitieslak koleksi ini. Anakanak dan orang tua yang menjadi adopsi, bisa menjadi adopsi lestari atau adopsi akhir. Mereka menggunakan AudioBuku apakah hanya digunakan sementara saja atau terus berkelanjutan menggunakan AudioBuku. Dan bahkan menolak. Apabila mereka menjadi adopsi lestari, mereka menjadikan AudioBuku sebagai kebutuhan media pembelajaran tambahan, atau bagian dari perpustakaan digital. Lain halnya dengan adopsi akhir. Mereka menggunakan AudioBuku sebagai hiburan semata yang akan diakses waktu-waktu tertentu saja. Malah, bisa jadi mereka akan menolak karena merasa tidak sesuai atau tidak nyaman dengan isi audio yang dihadirkan AudioBuku.

\section{E. KESIMPULAN}

Sesuai penjelasan penelitian di atas, maka dapat ditarik kesimpulan bahwa AudioBuku sebagai aplikasi media pembelajaran tambahan pencarian literatur. Anak-anak dapat membaca buku berbentuk audio tanpa mengganti peranan buku tercetak. Dalam tahap inovasi, tampilan AudioBuku menarik minat anak-anak untuk mendengarkan suara buku cerita rakyat. Koleksi cerita rakyat ada yang dikenakan biaya dan tanpa dikenakan biaya untuk mengaksesnya. Dalam tahap difusi, media AudioBuku dalam genggaman HP dapat mudah diakses oleh anak-anak dan orang tua. Dalam tahap adopsi, sebagian besar anak-anak dan orangtua menjadi adopsi lestari dan adopsi akhir. 


\section{DAFTAR PUSTAKA}

Bunanta, Murti. 2008. Buku, Mendongeng Dan Minat Membaca. Jakarta: Kelompok Pencinta Bacaan Anak.

Clark, Leilani. 2007. "Speaking Pictures: The Role of Sound and Orality in Audio Presentations of Children's Picture Books." New Review of Children's Literature and $\begin{array}{lllll}\text { Librarianship } & 9 & \text { (1): } & 1-19 . & \text { http://sci- }\end{array}$ hub.tw/https://doi.org/10.1080/1361454032000232077.

Edifikasi Media Indonesia. 2019. "Kumpulan Dongeng Cerita Rakyat.” Jakarta: Edifikasi Media Indonesia.

Endarmoko, Eko. 2007. Tesaurus Bahasa Indonesia. 2nd ed. Jakarta: Gramedia Pustaka Utama.

Family Health International. 2012. "Qualitative Research Methods: A Data Collector's Guide." Https://Atlasti.Com. https://course.ccs.neu.edu/is4800sp12/resources/qualmethods.pdf.

Gray, H. Joey; Davis, Phillip; Liou, Xiaou. 2017. "Keeping up with the Technologically Savvy Student: Student Perceptions of Audio Books." SCHOLE: A Journal of Leisure Studies and Recreation Education 26 (2): 28-38. http://scihub.tw/https://doi.org/10.1080/1937156X.2011.11949678.

Harrison, Helena, Birks, Melanie, Franklin, Richard, \& Mills, Jane. 2017. "Case Study Research: Foundations and Methodological Orientations." FQS (Forum Qualitative Social Social Research) 18 (1): 19. http://www.qualitativeresearch.net/index.php/fqs/article/view/2655/4079\#g31.

LaMorte, Wayne W. 2016. "Diffusion of Innovation Theory." Http://Sphweb.Bumc.Bu.Edu. $\quad$ http://sphweb.bumc.bu.edu/otlt/MPHModules/SB/BehavioralChangeTheories/BehavioralChangeTheories4.html.

Rubery, Matthew. 2008. "Play It Again, Sam Weller: New Digital Audiobooks and Old Ways of Reading." Journal of Victorian Culture 13 (1): 58-79. http://scihub.tw/https://doi.org/10.3366/E1355550208000088.

Ruzzene, Attilia. 2011. "Book Reviewes: The Case Study as Research Method: A Practical Handbook Yves-Chantal Gagnon.” International Studies in the Philosophy of Science 25 (3): 293-96. doi:https://doi.org/10.1080/02698595.2011.605251.

Sidik, Muksin. 2016. "Tahapan Difusi Inovasi Komunikasi Instruktif: Studi Deksriptif Kualitatif Pada Komunikasi Instruktif Di Palang Pintu Perlintasan PT Kereta Api Indonesia (Skripsi)." Yogyakarta, UIN Sunan Kalijaga. http://digilib.uinsuka.ac.id/23969/1/11730118_BAB-I_IV-atau-V_DAFTAR-PUSTAKA.pdf.

Stern, Catherine. 2011. "The Role of Audiobooks in Academic Libraries." College \& Undergraduate Libraries $18 \quad$ (1): 77-91. http://scihub.tw/https://doi.org/10.1080/10691316.2011.550532. 